\title{
Towards appreciating the importance of windowscapes: Evaluation and suggestion for improvement of New Zealand Building Code
}

\author{
* Leila Mirza ', Hugh Byrd 2 \\ 1 Building Control Department, Auckland Council, Auckland, New Zealand \\ 2 The University of Lincoln, Lincoln, United Kingdom
}

\begin{tabular}{|l|}
\hline A R T I C L E I N F O: \\
\hline Article history: \\
Received 20 August 2017 \\
Accepted 23 August 2017 \\
Available online 24 August \\
2017 \\
\hline Keywords: \\
Windowscapes; \\
Building code clause \\
and acceptable \\
solution; \\
Health and well-being; \\
Visual awareness of the \\
outdoor environment.
\end{tabular}

\begin{abstract}
A B S T R A C T
Rapid intensification of Auckland has made our visual awareness of the outdoor environment (windowscapes) more confined and restricted. The recent changes of Auckland's windowscapes have made the shortcomings of New Zealand Building Code more apparent. This paper aims to demonstrate the importance of windowscapes in urban dwellers' life and suggest some changes to current building code to provide healthier and liveable indoor environments. First, evidence from the literature on the impact of views on building occupants' wellbeing will be reviewed. Then, New Zealand Code Clause (G7 Natural light) and its Acceptable Solution will be critically analysed to identify areas that require improvement.

Our literature review indicates that private views are more relevant for health and wellbeing than building and planning legislation in New Zealand currently considers them to be. Hence, this paper suggests that windowscapes should become an essential part of future building codes and standards. This paper concludes that providing strict requirements regarding windowscapes is essential to building a healthier indoor environment.

CONTEMPORARY URBAN AFFAIRS (2018) 2(1), 55-65. Doi: 10.25034/ijcua.2018.3656
\end{abstract}

\section{Introduction}

1.1 The importance of windowscapes for urban dwellers

Windows have many roles: providing views, daylight, and ventilation. With the advent of buildings with large areas of glazing, increased time spent in buildings and increased awareness of the benefits of improved working environments, the importance of windows for building occupants has shifted in favour of windowscape. The provision of permanent supplementary artificial lighting and ventilation reduced the role of the window as the only source of daylight and fresh air, while the concept of transparency in architecture introduced a new type of relationship with the

\footnotetext{
*Corresponding Author:

Building Control Department, Auckland Council, Auckland, New Zealand

E-mail address: Leila.mirza@hotmail.co.nz
} 
landscape outside. This was coincident, and possibly the result of, changes in the lifestyle of modern urban dwellers who spend the majority of their time indoors (Shoemaker, 2002, p. 141). In agreement with this, McLain and Rogers (1981) say that despite fresh air and natural light remaining the major functions of windows, people are more interested in window as a way of contact with the outside world.

The importance of having a view for urban dwellers is confirmed in most studies on windows. Wells (1965) found that $89 \%$ of surveyed office workers stressed the importance of having access to the window even when there was abundant artificial light in the interior. An analysis (Nichols, 1977) of sixty questionnaires from volunteer participants working in an urban high-rise office building revealed that respondents without window views made more non job-related trips away from their workstations presumably looking for a view to the outside - than respondents with views. Nagy et al. (1995) found that respondents from an underground office rated the importance of having a view much higher than those from aboveground offices. Both groups considered the view as the most important function of a window, followed by fresh air and natural light. According to the literature review by Farley and Veitch (2001, p. 8) "of all the benefits and psychological functions provided by windows the provision of a view appears to be most valued by building occupants." In Bodart and Deneyer's (2004) survey, sunlight and visual contact with the outside were found to be the two most positive functions of windows for building users. Ne'Eman (1974) interviewed 647 users in four types of buildings (houses, school, offices and hospitals) and asked them how they would choose between a window providing sunlight into their interiors but with an unpleasant view and a window providing a pleasant view but without sunshine. The result revealed most would prefer a nice view through their windows to the provision of sunshine. CooperMarcus (1982) argued that attractiveness of neighbourhoods mainly depended on what residents could see from their windows. These results can be explained by the theory that humans have evolved to crave visual information about their environmental surroundings (Kaplan \& Kaplan, 1977; Verderber, 1986; Arenibafo, 2016).

\section{Literature review on preferred}

\section{windowscapes}

\subsection{Factors influencing preferences for windowscapes}

Windowscape plays a crucial role in modern life for urban dwellers as the majority of their time is spent indoors. The visual quality of urban windowscapes can, consequently, have a great influence on the quality of life. But what factors can influence windowscape preferences and what are the most and least visually preferred features of urban windowscapes? Answering these questions are important as preferences reflect how given environments support well-being (e.g. Van den Berg et al. (2003)).

Research shows that two main factors influence preferences for urban windowscapes: environmental characteristics and attributes of observers. This section only summarises key environmental factors, for more comprehensive literature review refer to Mirza (2015) and Lothian (2000). Environmental characteristics can be divided further into concrete features of urban landscape (e.g. water, greenery, sky, buildings) and psychological landscape descriptors (e.g. complexity and mystery).

Buildings: Since buildings are an inevitable component of urban windowscapes, two key questions for designers and developers are: how can buildings be incorporated in an urban scene to positively increase the visual quality of the views? And what characteristics of buildings are more highly valued by viewers? Kfir et al. (2002) found the presence of residential buildings in the near distance were the most influential factor in negative assessments of the view. However, if the buildings were more than 500 meters away or if the window outlook included a view of the sea, buildings had no effect on view preference. Tuaycharoen (2006) asked 20 students to assess how interesting they found the views of ten rooms in different buildings; a concrete wall with little 
colour variation was chosen as the least interesting view. Similarly, in a hospital context, rooms with large windows towards a concrete building were disliked (Verderber, 1986).

Low preference for obscuring buildings might be related to the associated loss of occupants' privacy. For instance, Markus \& Gray (1973) found the satisfaction with windows in residential dwellings depends on the number of buildings visible and their infringements upon privacy. In line with these findings, Mirza (2015) noted that blocking buildings were more negatively assessed in home views than office views. This result is due to different levels of visual privacy needed in these two contexts.

Cityscapes: $88 \%$ of the office workers $(n=348)$ in Markus' study (1967) preferred to see the distant city and landscape from their windows. A cityscape was rated higher than views showing close natural features (Tuaycharoen, 2006).

Landmarks: Landmarks to be the most preferred built feature of urban windowscapes. In some cases even a silhovette of a landmark on the horizon has the power to positively influence the observers (Mirza, 2015).

Roading: Roading (e.g. streets, highways, and parking lots) can negatively influence assessment of a scene. Parking lots and traffic were identified as two prominent disliked features of urban landscapes and windowscapes (Nasar, 1998; Hellinga, 2013). Weber et al. (2008) found streetscapes were considered more beautiful if the street is broad and laterally bounded by trees with only a few buildings visible.

Sky: The ability to see the sky from the window can keep observers in touch with information such as seasonal changes, time of day and the weather (Markus, 1967, p. 103) and was found to be a main reason behind a desire for windows (Keighley, 1973). Butler and Biner's (1989) research reported a view of outside for temporal information (weather and time of day) to be the strongest predictor of window size preferences. Office workers who could see the sky, were less likely to report fatigue, headache and eye strain problems (Heschong Mahone Group, 2003). While it has been found that a view dominated by sky is more satisfying than a view without this feature (Lottrup, Stigsdotter, Meilby, \& Claudi, 2013), the sky alone cannot evoke positive feelings in observers (Markus, 1967).

Greenery: Greenery was found by a significant number of researchers to be the most effective addition to a view for improving the visual quality of: commercial highway strips (Lambe \& Smardon, 1986; Smardon \& Goukas, 1984), residential areas (R. Kaplan, 1985; Hussain \& Byrd, 2012) and streetscapes (Stamps, 1997; Weber et al., 2008). However, it is not the case that all kinds of vegetation are equally preferred. Lottrup et al.'s (2013) research on workplace window views found that flowers, trees and park-like environments increased the odds of being satisfied with the views, while no significant relationship was found for mowed lawns and wild self-seeded natural environment. Participants in Gorman's survey study (2004) identified "trees block visibility" as one of the negative attribute of street trees. Results from Mirza's study (2015) adds to these findings by demonstrating that positive influence of greenery is more effective in blocked and semi-blocked views than long open views. Such results are important for application: if a view to a blocking building is inevitable when designing a new building, the architect should try to minimize the negative influence of a blocked view by providing greenery.

Water: The positive effect of water on preferences has been consistently reported (Nasar, 2000; White et al., 2010; Mirza, 2014). White et al. (2010) found that the extent of aquatic features in a built environment might be less important in influencing preferences than their mere presence.

Complexity: Complexity is a positive and influential predictor of preferences for urban window views (Collins, 1975; Markus, 1967; Rahbarianyazd, 2017). Wolf (2003) found that the increase of complexity of urban scenes by disliked features (e.g. buildings, and overhead wires) could negatively affect 
preferences. S. Kaplan (1987) reported that natural landscapes were preferred over urban scenes regardless of the level of complexity. Mirza (2015) found that the effect of complexity on preferences depends on the context of the views. While the complexity was a significant predictor of preferences for office windowscapes, no relationship was found for home views. The researcher explained her result by suggesting that observers in their office are more likely to be mentally fatigued due to the need of staying engaged with their everyday tasks and fighting off distractions compared to when they are at home. As a complex scene can effectively contribute to restoration, the higher preferences for complex views in offices is the result of observers' greater need to recover from mental fatigue.

Openness: Openness is a key driver of preferences (Kaplan \& Kaplan, 1989). Openness of an urban view depends on the density and configurations of buildings (Hur, Nasar, \& Chun, 2010), as well as the storey level where the window is located (Kfir et al., 2002). Hellinga and Hordijk, (2008) asked their respondents to choose which of six pictures they preferred most and least as a view from their offices. A wide view from a high floor was the most appreciated and a view from the ground floor to a close building was preferred the least. Ozdemir (2010) found identical offices to be experienced differently, depending on their views. Office workers with open expanded views perceived their rooms to be larger and lighter, and thus more satisfying, than those with closed views.

\subsection{The benefits of preferred windowscapes}

Research has shown that windowscapes can have economic value depending on their content. For instance, a pleasant view can lead to a considerable increase in house price (e.g. Luttik (2000)); while an unpleasant view could be expected to lead to a decrease in the house price. Factors that increase the value of a property include (in descending order of importance) view to the sea, view to urban parks, view from high-rise apartments and view to sparsely populated regions (Damigos \& Anyfantis, 2011). Full views to the ocean could increase the market price of singlefamily homes in Washington by almost $60 \%$ (Benson, et al. 1998). Similarly, a wide water view could increase the mean sale price of residential properties in Auckland as much as $44 \%$ (Samarasinghe \& Sharp, 2008). In Singapore, an unobstructed sea view from a high-rise building could add an average of $15 \%$ to the property price (Yu, Han, \& Chai, 2007).

Windowscapes have different beneficial values depending on their content. R. Kaplan (1993) reported that employees with desk jobs with a window to natural features (i.e., trees, vegetation, plants and foliage) had fewer ailments, were less frustrated and more satisfied with their jobs. Window views of green vegetation or water, rather than of other buildings or a brick wall, were found to have a positive effect on attention capacity (Tennessen \& Cimprich, 1995). Leather et al. (1998) added to this finding by demonstrating that natural features within a view can buffer the negative effect of job stress on intention to quit and a marginal positive effect on general well-being.

The Heschong Mahone Group (2003) found a significant correlation between the content of the views and reports of fatigue, headache, difficulty concentrating and influenza. The study also found office workers with interesting views performed $10 \%$ to $25 \%$ better on tests of mental function and memory recall than those with no view. Shin (2007) documented positive self-rated health effects of viewing forests through a window on office workers in Seoul, South Korea. A cross-sectional survey on office workers in the Netherlands showed that attractive window views reduced discomfort (e.g. concentration problems and headache) (Aries, Veitch, \& Newsham, 2010). A recent study by Lottrup et al. (2013) showed that a view of natural elements was related to high view satisfaction, which then contributes to high work ability and high job satisfaction. Research in this area shows that an attractive windowscape is more than an amenity and underpinning this preference is a fundamental issue of psychological well-being and physical comfort (Tuaycharoen \& Tregenza, 2007).

Heerwagen and Orians (1986) investigated whether employees who work in windowless offices 
use visual decoration to compensate for the lack of having access to a window. Those who worked in windowless offices used more visual materials for decoration than occupants of windowed spaces. The content of the décor in windowless offices was dominated by nature themes. Bringslimark et al. (2011) reported similar results. Bringslimark et al. (2011) noted that workers in windowless offices were more likely to bring plants and pictures of nature into their workspaces than workers with windows. Radikovic, (2005) argued that an artificial window video would be an excellent replacement for a window in all single-person spaces with a limited view of nature, such as underground, underwater, outer space, or just strictly urban areas. However, a research conducted by Kahn Jr. et al. (2008) showed that a plasma window was no more restorative than a blank wall.

The physiological effect of windowscape is not limited to workplaces. Patients with a view to stands of trees were found to recover faster and required less pain medication than patients facing a brick wall (Ulrich, 1984). Prison inmates whose view consisted of adjacent farmlands had lower rates of sick call than those looking out upon the prison yard (Moore, 1981). An archival study of past residents of a nursing home revealed a significant negative correlation between people view (view to parking lots, the front entrance, or a yard) and length of stay, while view of greenery had no effect on this matter (O'Connor, Davidson, \& Gifford, 1991).

Having natural elements in the home window views contributes substantially to residents' satisfaction with their neighbourhood and their sense of wellbeing (R. Kaplan, 2001). Taylor, Kuo, and Sullivan (2002) found concentration and self-discipline of inner-city girls (but not boys) were positively affected by the naturalness of the view from their high-rise urban homes. The authors explained their results by suggesting that boys typically spent less time indoors. Residents living in greener surroundings reported to have a lower level of fear, fewer incivilities and less aggressive and violent behaviour (Kuo \& Sullivan, 2001). Residents of a large metropolitan area in the U.S. rated the potential of trees for helping people feel calmer as one of the key benefits of this natural feature (Lohr et al. 2004). Having a view over gardens has been shown to have a strong contribution to neighbourhood satisfaction (R. Kaplan, 2001; Kearney, 2006); moreover, those whose homes had access to their own garden or to shared gardens had significantly better health (Macintyre et al., 2003). Surprisingly, R. Kaplan (1985) noted that urban parks and large grassy open spaces played a minor role, at best, in residents' ratings of satisfaction with various aspects of the neighbourhood; while the availability of nearby trees and well-landscaped grounds were the two most important factors. Although, from these studies, it can be concluded that viewing natural features through windows has positive psychological effects, it is still not clear which features have contributed most (Velarde, Fry, \& Tveit, 2007).

College students living on higher floor levels with open views found their dormitory rooms less crowded and got along better with their roommates (Schiffenbaver, 1979). Undergraduate university students who had views to a lake and trees from their dormitory windows were better able to concentrate than those students with views to city streets, buildings or a brick wall (Tennessen \& Cimprich, 1995). Students who were asked to imagine themselves cognitively fatigued, rated settings with views of large natural murals with water more restorative than settings with window views of real, but mundane nature with built structures present (Felsten, 2009).

There is a series of laboratory studies that adds to our understanding of the psychological value of viewing attractive scenes. For instance, experimental research by Tuaycharoen and Tregenza (2007) found less discomfort to be caused by glare from a window when the window offered an interesting view than from a window of the same mean luminance but with a view of less interest. The authors previously conducted a similar study in a laboratory condition with images of scenes, which led to similar findings (Tuaycharoen \& Tregenza, 2005). Purcell et al. (2001) found nature scenes with water were rated higher in restorativeness than nature scenes without water. Karmanov and Hamel (2008) study added to this finding by 
showing urban environments with an outlook onto water could have the same stress-reducing and mood-enhancing power as a natural environment. This may suggest that water bodies can compensate for the lack of greenery in urban environments.

\section{Critiques of New Zealand Building Code G7}

In light of previous finding on the importance of windowscapes on urban dwellers' life, this section critically reviews the current New Zealand Building Code (NZBC) G7 Natural light and its Acceptable Solution.

As a performance-based regulation, the Building Code sets the standards that all building work must meet to protect health and safety of building occupants. In practice, 'performance-based' means that any design and construction methods can be used as long as they can prove that the requirements of the Building Code have been met. This flexibility encourages the construction industry to develop innovative and cost-effective solutions. Most clauses in The Building Code have Acceptable Solutions or Verification Methods describing how to meet the performance requirements of the particular clause. Although Acceptable Solutions and Verification Methods are not mandatory, designs based on them must be accepted by Building Consent Authorities.

G7 Natural Light is aimed to ensure that there is sufficient natural light and visual awareness of the outside environment for building occupants. Like other NZBC technical clauses, G7 contains three main sections: objective, functional requirement, and performance criteria. Stating its objective is to "safeguard people from illness or loss of amenity due to isolation from natural light and the outside environment", G7 appreciates the importance of windowscape on health and wellbeing of building occupants (Brookers Building Law Handbook, 2012, p. 355).

The functional requirement specifies that "habitable spaces shall provide adequate openings for natural light and for visual awareness of the outside environment" (ibid. p. 355). However, G7 puts limits on this requirement making it only mandatory for 'habitable spaces' within 'housing', 'old people's homes' and 'early childhood centers'. In other words, offices or student accommodation can be built with no or limited access to the outside views. That is while our literature review showed the significance of window views on the health and productivity of office workers and students. Moreover, functional requirement of G7 (G7.2) appears equivocal as there is no clear definition for 'adequate opening': "adequate to achieve the objectives of the Building Codes". This is also the case for "visual awareness', leaving it open to any interpretation. For instance, it can be easily interpreted that G7 does not require a habitable space to have a street or landscape view and as long as one can differentiate between day and night, and diverse weather conditions, the requirement of the code are met. In other words, a view to a brick wall a few meters away from an observer can comply with the building code; however, if such views can safeguard people from 'illness or loss of amenity' is most certainly in question.

Two performance criteria are used to fulfil the requirements of NZBC G7. As this research is only dealing with the visual awareness of the outside requirement (G7.3.2) of Clause G7, there will be no mention of the illuminance requirements (G7.3.1) unless it is deemed required. G7.3.2 performance criteria explain that "openings to give awareness of the outside shall be transparent and provided in suitable locations" (ibid p. 355). The code does not define any criteria to determine a suitable location for a window. It can be argued that the best practice is to ensure that the visual privacy of the occupants is secured while a desirable view is achieved. However, the lack of knowledge on influence of windowscapes preferences on wellbeing made architects to become more concerned with how the building looks from the outside and hence give the location of the window from inside less priority.

Using the guides in acceptable solution in G7 to design new buildings can be counted as a one of the main reasons for current lack of sufficient visual awareness in most habitable spaces. The Acceptable Solution (G7/AS1) is divided into two 
parts: vertical windows in external walls and awareness of the outside environment. However, the emphasis has been more put on natural lighting, while the importance of window views is overlooked. For instance, G7/AS1 suggests overcoming the impact of obstruction in a view on the amount of natural light entering a building by using high reflectance surfaces. That is while no comments have been made on the impact of obstruction on the quality of the windowscape or how to compensate this. Moreover, G7/AS1 allows visual awareness of the outside environment through another space making this issue even more critical.

Although this section only focuses on G7 but the following shortcomings in current building and planning regulations have been noted that deserves further investigations in future work: 1) The possible impact of future development on windowscapes of adjacent properties hasn't been considered in the Building Act and the Building Code. This particularly becomes more important in mixed zoning areas, as a new office building can get constructed on the boundary and block an exterior view of an existing next-door apartment building; 2) The fact that views from a private domain are not considered important under the current Resource Management Act (2017); 3) The openness of windowscapes hasn't been considered important in Auckland's new planning rule book. Based on the new unitary plan, a minimum net site area for the mixed housing suburban zone is $400 \mathrm{~m} 2$ and for the mixed housing urban zone is only $300 \mathrm{~m} 2$. Only one-meter setbacks from the side and rear boundaries are required. These rules are changing Auckland's windowscapes and soon a building within a short distance becomes a common feature within all residential windows.

\section{Conclusions}

Windowscape is an aspect of health and safety that is at risk of being compromised due to insufficient regulation. Our literature review indicates that private views are more relevant for health and wellbeing than building and planning legislation in New Zealand currently considers. Hence, this paper suggests that windowscape should become an essential part of future building codes and standards. In particular, G7 needs to extend to include buildings that are occupied on a regular basis and for extended periods of time such as working environment, offices and student accommodation. Moreover, it is important that G7 enforces remediation where there is an obstruction in the view. This is because our literature review shows that an attractive windowscape is more than an amenity and underpinning this preference is a fundamental issue of psychological well-being and physical comfort. For instance, if a view to a building is blocked when designing a new building, the architect should try to minimize the negative influence of a blocked view using developing technologies such as green walls. The fact that the NZBC is performance-based and not prescriptive, can make profit-driven property developers lean more towards 'liberal interpretation'. This paper believes that providing strict requirements regarding windowscapes is essential to building a healthier indoor environment. For instance, strict requirements can make designers to consider windowscapes in their initial designs rather than adding component retrospectively to compensate the lack of such amenity.

\section{References}

Appleton, J. (1975). Landscape Evaluation: The Theoretical Vacuum. Transactions of the Institute of British Geographers, (66), 120-123.

Aries, M. B. C., Veitch, J. A., \& Newsham, G. R. (2010). Windows, view, and office characteristics predict physical and psychological discomfort. Journal of Environmental Psychology, 30(4), 533-541.

Arenibafo, F. (2016). The Transformation of Aesthetics in Architecture from Traditional to Modern Architecture: A case study of the Yoruba (southwestern) region of Nigeria. Contemporary Urban Affairs (JCUA), 1 (1), 3544. Doi: 10.25034/1761.1(1)35-44

Benson, E. D., Hansen, J. L., Schwartz, A. L., \& Smersh, G. T. (1998). Pricing Residential Amenities: The Value of a View. The Journal 
of Real Estate Finance and Economics, 16(1), 55-73.

Bodart, M., \& Deneyer, A. (2004). Analyse of the survey on the office workers' interest in windows. IEA 31- Subtask A., working document, 2004

Bringslimark, T., Hartig, T., \& Patil, G. G. (2011). Adaptation to Windowlessness: Do Office Workers Compensate for a Lack of Visual Access to the Outdoors? Environment and Behavior, 43(4), 469-487.

Brookers Building Law Handbook. (2012). New Zealand: Thomson Reuters.

Butler, D. L., \& Biner, P. M. (1989). Effects of Setting on Window Preferences and Factors Associated with Those Preferences. Environment and Behavior, 21 (1), 17-31.

Collins, B. L. (1975). Windows and people: A literature survey. NBS Building Science Series, 70.

Cooper-Marcus, C. (1982). The aesthetics of family housing: the residents' viewpoint. Landscape Res., 7, 9-13.

Damigos, D., \& Anyfantis, F. (2011). The value of view through the eyes of real estate experts: A Fuzzy Delphi Approach. Landscape and Urban Planning, 101 (2), 171-178.

Farley, K. M., \& Veitch, J. A. (2001). A room with a view: a review of the effects of windows on work and well-being.

Felsten, G. (2009). Where to take a study break on the college campus: An attention restoration theory perspective. Journal of Environmental Psychology, 29(1), 160-167.

Gorman, J. (2004). Residents' opinions on the value of street trees depending on tree location. Journal of Arboriculture, 30(1), 36-44.

Heerwagen, J. H., \& Orians, G. H. (1986). Adaptations to Windowlessness A Study of the Use of Visual Decor in Windowed and Windowless Offices. Environment and Behavior, 18(5), 623-639.

Hellinga, H. (2013). Daylight and View: The influence of windows on the visual quality of indoor spaces (PhD thesis). Delft University of Technology.
Hellinga, H., \& Hordijk, T. (2008). Preferences of office workers regarding the lighting and view out of their office. In SOLG Symposium Light, Performance and Quality of Life (pp. 26-29).

Heschong Mahone Group. (2003). Windows and Offices: a Study of Office Worker Performance and the Indoor Environment: Technical Report. California Energy Commission.

Hur, M., Nasar, J. L., \& Chun, B. (2010). Neighborhood satisfaction, physical and perceived naturalness and openness. Journal of Environmental Psychology, 30(1), 52-59.

Hussain, N. H. M., \& Byrd, H. (2012). Towards a Compatible Landscape in Malaysia: An Idea, Challenge and Imperatives. Procedia Social and Behavioral Sciences, 35, 275-283.

Kahn Jr., P. H., Friedman, B., Gill, B., Hagman, J., Severson, R. L., Freier, N. G., ... Stolyar, A. (2008). A plasma display window?-The shifting baseline problem in a technologically mediated natural world. Journal of Environmental Psychology, 28(2) 192-199.

Kaplan, R. (1985). Nature at the doorstep: Residential satisfaction and the nearby environment. Journal of Architectural and Planning Research.

Kaplan, R. (1993). The role of nature in the context of the workplace. Landscape and Urban Planning, 26(1-4), 193-201.

Kaplan, R. (2001). The Nature of the View from Home. Environment and Behavior, 33(4), 507 $-542$.

Kaplan, R., \& Kaplan, S. (1989). The experience of nature: a psychological perspective. CUP Archive.

Kaplan, S. (1987). Aesthetics, Affect, and Cognition Environmental Preference from an Evolutionary Perspective. Environment and Behavior, 19(1), 3-32.

Kaplan, S., \& Kaplan, R. (1977). Humanscape: Environments for People. Ann Arbor, Mich.: Ulrichs Books. 
Karmanov, D., \& Hamel, R. (2008). Assessing the restorative potential of contemporary urban environment(s): Beyond the nature versus urban dichotomy. Landscape and Urban Planning, 86(2), 115-125.

Kearney, A. R. (2006). Residential Development Patterns and Neighborhood Satisfaction Impacts of Density and Nearby Nature. Environment and Behavior, 38(1), 112-139.

Keighley, E. C. (1973). Visual requirements and reduced fenestration in office buildings-A study of window shape. Building Science, 8(4), 311-320.

Kfir, I. Z., Munemoto, J., Sacko, O., \& Kawasaki, Y. (2002). Evaluation of the view from the dwelling units on manmade islands in Osaka bay. Multiple regression analysis based on residents' evaluation and image processing of photographs taken from the living room. Journal of Architecture, Planning \& Environmental Engineering, (554), 357-364.

Kuo, F. E., \& Sullivan, W. C. (2001). Environment and crime in the inner city. Environment and Behavior, 33(3), 343.

Lambe, R. A., \& Smardon, R. C. (1986). Commercial highway landscape reclamation: A participatory approach. Landscape Planning, 12(4), 353-385.

Leather, P., Pyrgas, M., Beale, D., \& Lawrence, C. (1998). Windows in the Workplace: Sunlight, View and Occupational Stress. Environment and Behavior, 30(6), 739-762.

Lohr, V. I., Pearson-Mims, C. H., Tarnai, J., \& Dillman, D. A. (2004). How urban residents rate and rank the benefits and problems associated with trees in cities. Journal of Arboriculture, 30(1), 28-35.

Lothian, A. (2000). Landscape Quality Assessment of South Australia (PhD Thesis). University of Adelaide.

Lottrup, L., Stigsdotter, U. K., Meilby, H., \& Claudi, A. G. (2013). The Workplace Window View: A Determinant of Office Workers' Work Ability and Job Satisfaction. Landscape Research, $0(0), 1-19$.

Luttik, J. (2000). The value of trees, water and open space as reflected by house prices in the
Netherlands. Landscape and Urban Planning, 48(3-4), 161-167.

Macintyre, S., Ellaway, A., Hiscock, R., Kearns, A., Der, G., \& McKay, L. (2003). What features of the home and the area might help to explain observed relationships between housing tenure and health? Evidence from the west of Scotland. Health \& Place, 9(3), 207-218.

Markus, T. A. (1967). The function of windows- A reappraisal. Building Science, 2(2), 97-121.

Markus, T. A., \& Gray, A. (1973). Windows in low rise, high density housing-the psychological significance of sunshine, daylight, view and visual privacy. Proceedings of Windows and Their Functions in Architectural Design, 22-27.

McLain, J., \& Rogers, K. E. (1981). Windows and user preferences. Journal of Interior Design, $7(2)$, $7-11$.

Mirza, L (2014), "Water Views: The Importance of Water on Urban Landscape Preferences," Building a Better New Zealand Conference, Auckland, New Zealand.

Mirza, L. (2015). Windowscapes: A Study of Landscape Preferences in an Urban Situation.

Mirza, L, Linzey M., \& Byrd H. (2012), "The Impact of Urban Background on Appreciation of Natural Environments," ICBEDC-2012: 6th International Conference and Workshop on the Built Environment in Developing Countries, Adelaide, Australia.

Moore, E. O. (1981). A prison environment's effect on health care service demands. Journal of Environmental Systems, 11 (1), 17-34.

Nagy, E., Yasunaga, S., \& Kose, S. (1995). Japanese office employees' psychological reactions to their underground and above-ground offices. Journal of Environmental Psychology, 15(2), 123-134.

Nasar, J. L. (1983). Adult Viewers' Preferences in Residential Scenes A Study of the Relationship of Environmental Attributes to Preference. Environment and Behavior, 15(5), 589-614.

Nasar, J. L. (1987). The effect of sign complexity and coherence on the perceived quality of retail 
scenes. Journal of the American Planning Association, 53(4), 499-509.

Nasar, J. L. (1988). Perception and evaluation of residential street scenes. Environmental Aesthetics: Theory, Research, and Application, 275-289.

Nasar, J. L. (1998). The evaluative image of the city. Sage Publications Thousand Oaks, CA.

Nasar, J. L. (2000). The evaluative image of places. Person-Environment Psychology: New Directions and Perspectives, 117-168.

Ne'Eman, E. (1974). Visual aspects of sunlight in buildings. Lighting Research and Technology, 6(3), 159-164.

Nichols, K. W. (1977). Urban office buildings: view variables. In D. J. Conway (Ed.), Human response to tall building (pp. 72-80).

O'Connor, B. P., Davidson, H., \& Gifford, R. (1991). Window View, Social Exposure and Nursing Home Adaptation. Canadian Journal on Aging/La Revue Canadienne Du Vieillissement, 10(03), 216-223.

Ozdemir, A. (2010). The effect of window views' openness and naturalness on the perception of rooms' spaciousness and brightness: A visual preference study. Scientific Research and Essays, 5(16), 2275-2287.

Purcell, T., Peron, E., \& Berto, R. (2001). Why do preferences differ between scene types? Environment and Behavior, 33(1), 93-106.

Radikovic, A. S. (2005). A true virtual window. Texas A\&M University.

Rahbarianyazd, R. (2017). Sustainability in Historic Urban Environments: Effect of gentrification in the process of sustainable urban revitalization. Journal of Contemporary Urban Affairs, 1(1), 1-9. Doi: 10.25034/1761.1(1)1-9

Samarasinghe, O. E., \& Sharp, B. M. H. (2008). The value of a view: A spatial hedonic analysis. New Zealand Economic Papers, 42(1), 59-78.

Schiffenbaver, A. (1979). Designing for High-Density Living. In J. R. Aiello \& A. Baum (Eds.), Residential Crowding and Design (pp. 229240). Springer US.

Shin, W. S. (2007). The influence of forest view through a window on job satisfaction and job stress. Scandinavian Journal of Forest Research, 22(3), 248-253.

Shoemaker, C. A. (Ed.). (2002). Interaction by Design: Bringing People and Plants Together for Heatlh and Well-Being (1st ed.). WileyBlackwell.

Smardon, R. C., \& Goukas, M. M. (1984). Village of North Syracuse main street assessment study. Occasional Paper ESF, 84-010.

Stamps, A. E. (1997). Some streets of San Francisco: preference effects of trees, cars, wires, and buildings. Environment and Planning B, 24, 81-94.

Taylor, A., Kuo, F. E., \& Sullivan, W. C. (2002). Views of nature and self-discipline: Evidence from inner city childern. Journal of Environmental Psychology, 22(1-2), 49-63.

Tennessen, C. M., \& Cimprich, B. (1995). Views to nature: Effects on attention. Journal of Environmental Psychology, 15(1), 77-85.

Tuaycharoen, N. (2006). The Reduction of Discomfort Glare from Windows by Interesting Views. University of Sheffield, School of Architecture.

Tuaycharoen, N., \& Tregenza, P. R. (2005). Discomfort glare from interesting images. Lighting Research and Technology, 37(4), 329-338.

Tuaycharoen, N., \& Tregenza, P. R. (2007). View and discomfort glare from windows. Lighting Research and Technology, 39(2), 185-200.

Ulrich, R. S. (1984). View through a window may influence recovery from surgery. Science, 224(4647), 420.

Van den Berg, A. E., Koole, S. L., \& van der Wulp, N. Y. (2003). Environmental preference and restoration:(How) are they related? Journal of Environmental Psychology, 23(2), 135-146.

Velarde, M. D., Fry, G., \& Tveit, M. (2007). Health effects of viewing landscapes - Landscape types in environmental psychology. Urban Forestry \& Urban Greening, 6(4), 199-212.

Verderber, S. (1986). Dimensions of Person-Window Transactions in the Hospital Environment. Environment and Behavior, 18(4), 450-466.

Weber, R., Schnier, J., \& Jacobsen, T. (2008). Aesthetics of streetscapes: Influence of 
fundamental properties on aesthetic judgments of urban space. Perceptual and Motor Skills, 106(1), 128-146.

Wells, B. W. P. (1965). Subjective responses to the lighting installation in a modern office building and their design implications. Building Science, 1 1 1), 57-68.

White, M., Smith, A., Humphryes, K., Pahl, S., Snelling, D., \& Depledge, M. (2010). Blue space: The importance of water for preference, affect, and restorativeness ratings of natural and built scenes. Journal of Environmental Psychology.

Wolf, K. L. (2003). Freeway roadside management: the urban forest beyond the white line. Journal of Arboriculture, 29(3), 127-136.

Yu, S., Han, S., \& Chai, C. (2007). Modelling the value of view in high-rise apartments: a 3D GIS approach. Environment and Planning B Planning and Design, 34(1), 139. 